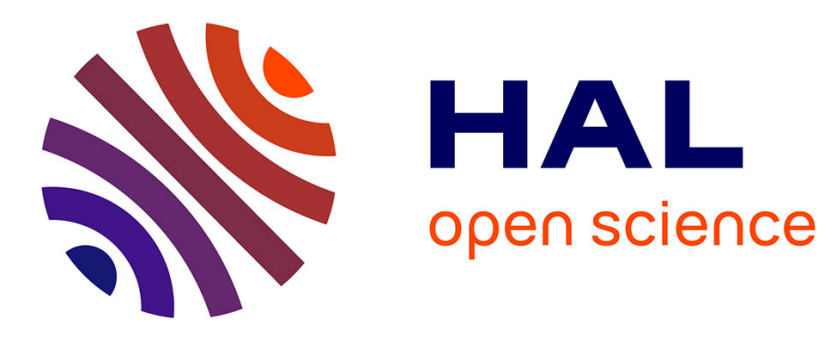

\title{
Towards an Agile and Collaborative Platform for Managing Supply Chain Uncertainties
}

Matthieu Lauras, Jacques Lamothe, Frederick Benaben, Beatriz Andres, Raul Poler

\section{- To cite this version:}

Matthieu Lauras, Jacques Lamothe, Frederick Benaben, Beatriz Andres, Raul Poler. Towards an Agile and Collaborative Platform for Managing Supply Chain Uncertainties. 6th International IFIP Working Conference on Enterprise Interoperability (IWEI), May 2015, Nîmes, France. pp.64-72, 10.1007/978-3-662-47157-9_6. hal-01438408

\section{HAL Id: hal-01438408 \\ https://hal.inria.fr/hal-01438408}

Submitted on 17 Jan 2017

HAL is a multi-disciplinary open access archive for the deposit and dissemination of scientific research documents, whether they are published or not. The documents may come from teaching and research institutions in France or abroad, or from public or private research centers.
L'archive ouverte pluridisciplinaire HAL, est destinée au dépôt et à la diffusion de documents scientifiques de niveau recherche, publiés ou non, émanant des établissements d'enseignement et de recherche français ou étrangers, des laboratoires publics ou privés.

\section{(c)(1)}

Distributed under a Creative Commons Attribution| 4.0 International License 


\title{
Towards an Agile and Collaborative Platform for Managing Supply Chain Uncertainties
}

\author{
Matthieu Lauras ${ }^{1}$, Jacques Lamothe ${ }^{1}$, Frederick Benaben ${ }^{1}$, Beatriz Andres ${ }^{2}$, \\ Raul Poler ${ }^{2}$ \\ ${ }^{1}$ Université Toulouse, Mines Albi, Campus Jarlard, Route de Teillet \\ 81000 Albi, France \\ $\{$ lauras, lamothe, benaben\}@mines-albi.fr \\ ${ }^{2}$ Universitat Politecnica de Valencia, Camino de Vera s/n, \\ 46022 Valencia, Spain \\ \{bandres, rpoler\}@,cigip.upv.es
}

\begin{abstract}
Nowadays, one of the main challenges for Supply Chains is the management of disruptions and uncertainties. Turbulence and instability have now to be considered as the 'normal' situation. Future Supply Chains should be able to cope with this new context to stay competitive. To solve this issue, new approaches and technologies have to be designed in order to improve the agility capability of supply networks. To contribute to this new problem statement, as a part of the H2020 C2NET research project, this paper proposes a concrete research framework. The research aim consists in defining precise research orientations in one hand, and structuring a set of technical tasks able to result in an agile and collaborative platform on the other hand. Basically, the main components of the research framework are presented and the expected impacts are discussed.
\end{abstract}

Keywords: Supply Chain, Uncertainty, Collaborative Platform, Agility, Research Framework.

\section{Introduction}

Modern Supply Chains are continuously challenged by unexpected disruptive events that are increasing in their frequency and effects: supply failures, demand changes, internal disruptions, etc. In this context, turbulence and instability can be no longer considered as an episodic crisis, rather the "norm" or the default status. The question is then to know how the Supply Chains can strive and gain in such disruptive environments and which supportive roles can the technology play. Current IT and decision-making systems are designed to run in more or less "stable" environment. Disturbances are captured by exception handling mechanisms. Thus, calling for a new perspective in Supply Chains design and engineering. While current Supply Chains are tempting to be robust, tomorrow's Supply Chains need to become agile. 
The current research work proposes to develop some innovative solutions to bridge this gap. This research project is a sub-part of the C2NET H2020 project (2015 2018) that covets leveraging the potential of Cloud technologies providing a manufacturing infrastructure for a real-time knowledge of different supply chain components such as manufacturing assets status, inventory levels or current demand at consumption points. By providing specific tools for optimization and collaboration in the cloud, companies involved in a Supply Chain will be able to increase their agility to respond quickly, flexibly and efficiently to changes in demand and unexpected events that have place during products supply. C2NET is providing a technological infrastructure that will enable a continuous data collection in real time from manufacturing processes that take place within a plant including logistics operations intra-plants, as well as from products, which are being processing along the whole supply chain. C2NET will facilitate its adaptation to actual manufacturing chains allowing data collection from a wide range of different information sources such as legacy systems (Enterprise Resources Planning, Manufacturing Execution Systems, Business Intelligence...), industrial control systems or directly from devices with different levels of intelligence built into machines and products such as smart sensors, embedded systems or Radio Frequency Identification. Collaboration throughout the Supply Chain using cloud-based tools and solutions is the main concept on which C2NET platform is based. This cloud platform is articulated around three main components as described in Figure 1:

- The C2NET Data Collection Framework (DCF) that collects in real-time information from processes and products within the supply chain;

- The C2NET Optimizer (OPT) that allows providing production plans and decisions to all concerned supply chain partners;

- The C2NET Collaboration Tools (COT) that proposes a set of services able to facilitate the achievement of agreements and drastically reduce response time and cost of decision-making processes.

In this paper we focus only on the collaboration tools (C2NET-COT). The problem statement of this set of tools is to develop a new approach for facilitating collaborative demand, production and delivery plans along the supply network. Basically, the technical ambition is to design a modular architecture for interoperability of intra plant and extra plant processes in conjunction with mobile, collaborative tools for data sharing, data analytics and knowledge-based systems, at factory and at supply network level.

The paper is split up into three main sections. First a literature selection will propose to underline the concepts of "Agile Supply Chains" and "Collaborative networks". On this basis, we will propose in a second part a research framework able to structure the future developments on this subject. Then, a third part will discuss the main impacts that should be obtained at the end of this research project. 


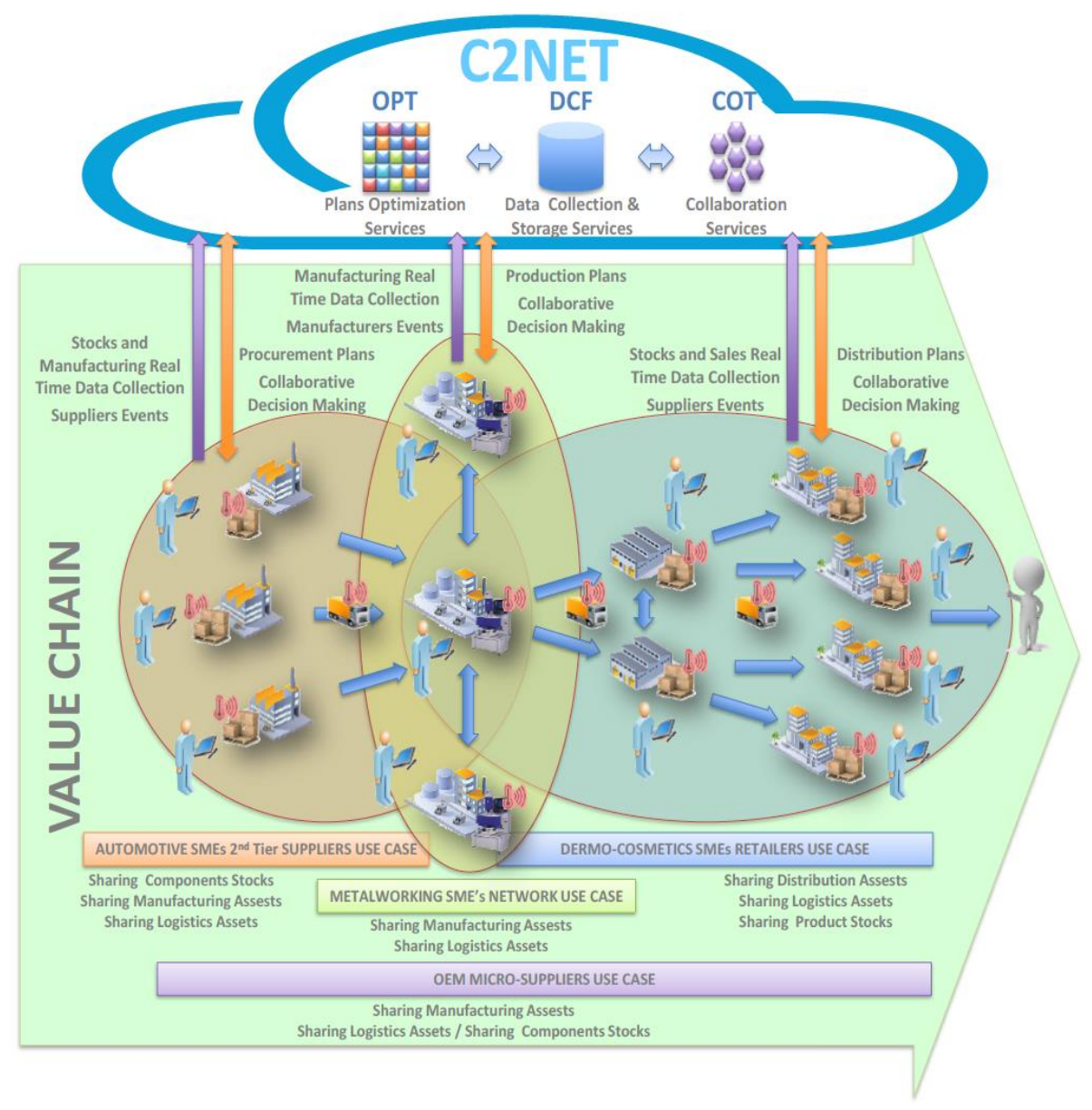

Fig. 1. Overview of the C2NET Project (platform and use cases).

\section{Literature Selection}

Many companies have not fully recognized the nature of systemic supply chain risk and have continued to focus on seeking efficiency improvements (Christopher and Peck, 2004). These authors argue that a new priority consist in searching for supply chain strategies that embody a significantly higher degree of resilience. Resilience implies flexibility and agility. Its implications extend beyond process redesign to fundamental decisions on sourcing and the establishment of more collaborative supply chain relationships based on far greater transparency of information (Christopher and Peck, 2004). 


\subsection{Agile Supply Chains}

According to Lee (2004), an agile supply chain is a set of partners responding quickly to short-term changes in demand (or supply) and handling external disruptions smoothly. Sometimes agility can be mistaken for other similar but different concepts such as adaptability, resilience and virtuality. Researchers also had interest on the capabilities that are required to access agility. Charles et al., (2010) justifies that agility requires the combination of:

- Effectiveness: ability to satisfy the customer demand;

- Completeness: ability to satisfy totally the customer demand;

- Reliability: ability to respect the customer delivery lead time;

- Responsiveness: ability to respond quickly which requires to: (i) detect quickly changes [Visibility], (ii) decide quickly on the adaptation to make using flexibility [Reactivity], and (iii) implement quickly the decisions [Velocity].

Another definition has been proposed by (Benaben, 2012):

Agility $=($ Detection + Adaptation $) \mathrm{x}($ Effectiveness + Responsiveness $)$

In the following we will keep this definition. Recently various initiatives have appeared for analyzing and supporting the deployment of agility in supply chain. Such initiatives are SOA and WebService based (Ahn et al., 2012; Ameri and Patil, 2012; Zhang et al., 2012). Accorsi, (2011) describes notably a specific SaaS, the Business Process as a Service (BPaaS). Ahn et al., (2012) discuss moreover the slow adoption of XML standards such as ebXML and RosettaNet in agile supply chains and identifies three pitfalls: (i) these standards are presently not adapted to agile supply chains which constrained by high market volatility and short customer lead times; (ii) lack of stringent, vendor-independent business process standards that create a barrier to achieving the high level alignment and flexibility; (iii) technologies for the management of online relationships are hardly accessible to SMEs because of a wide variety of partnering options that might be required, a large number of trading partners, product diversity, and strategic diversity. (Benaben, 2012) proposes a framework for differentiating the various strategies of workflow agility:

- Delayed choice: the process is partially defined during the design time and finalized at the execution. In this approach, the implementation of some subprocesses is chosen within a predefined list at the moment of the process execution. This approach is implemented in the YAWL system (Adams et al., 2005).

- Delayed design: the process is partially defined, but some sub-processes are not identified during the design. This approach suggests to come back to a specific design time when required during the execution.

- Risks management: various alternative paths are identified during the design time in order to adapt to risks, threats or opportunities. One path is finally chosen during each execution of the process. With this approach the number of paths to be identified can be too important in practice. 
- AdHoc design: this approach extends the concept of delayed design. The sequence of activities can be changed, some tasks can be added or cancelled or repeated. It is the more common approach (Adams et al., 2005).

The C2NET Collaborative Platform will propose a concrete support able to manage the agility of the collaborative situation, especially in manufacturing network environment. The main contribution of the C2NET Project regarding extent literature on this point consists in making agile Supply Chains concrete. Specific objectives will include the design and the implementation of an integrated system able to supervise, detect, adapt and assess the collaborative situation.

\subsection{Collaborative Networks}

The way how manufacturing and service industries manage their businesses is changing due to the emerging new competitive environments. According to (Camarinha-Matos and Afsarmanesh, 2005) the enterprises' success in the new dynamic environments is associated to the improved competencies in terms of new business models, strategies, governance principles, processes and technological capabilities of manufacturing enterprises of 2020. Moreover, especially for SMEs, the participation in collaborative networks is also a key issue for any enterprise that is willing to achieve differentiated and competitive strengths. Consequently, establishing collaborative relationships becomes an important issue to deal with customer needs, through sharing competencies and resources. Collaborative Networks consist of a variety of heterogeneous autonomous entities, geographically distributed, in which participants collaborate to achieve a common goal and base their interactions through computer networks. SMEs are characterized by limited capabilities and resources; therefore, in order to overcome possible barriers that can appear when establishing collaboration, joint efforts must be performed to achieve the desired collaborative scenarios. When establishing collaboration, networked partners share information, resources and responsibilities to jointly plan, implement, and evaluate a program of activities to reach a common goal and therefore jointly generate value. Thus, establish collaborative relationships imply sharing risks, resources, responsibilities, losses, rewards and trust. Collaborative networks manifest in a large variety of forms, such as virtual organizations, virtual enterprises, dynamic supply chains, professional virtual communities, collaborative virtual laboratories (Camarinha-Matos and Afsarmanesh, 2005) and collaborative non-hierarchical networks (Poler et al., 2013). The main challenges for creating collaborative networks are presented in VOmap and are divided into five focus areas (i) socio economic, (ii) VO management, (iii) ITC support services, (iv) ICT Infrastructures and (v) formal models and theories.

Based on this background, the C2NET project will focus on the research and technical development to overcome possible barriers encountered when enterprises participate in collaborative networks characterized by distributed partners with decentralized information. The C2NET project will allow exploiting enterprises' capabilities and resources to efficiently succeed on the participation in collaborative networks. Specific objectives will include the design of cloud computing ICT, due to the advantages encountered for manufacturing and service industry networks, and the 
development of an integrated framework, consisting of models, methodologies and tools, to support enterprises in dealing with decentralized decision making within collaborative networks.

\section{Research Framework}

Our research project aims at providing a Collaborative Manufacturing Network Platform with a set of tools in charge of managing the agility of the collaborative situation. These tools are specifically in charge of exploiting the gathered data in order to formalize a clear vision of the collaborative situation and to propose dynamic adjustments. The following specific objectives are targeted in this research framework:

- Supervision: Define and implement the exploitation mechanisms to use collected data (from IoT, from monitoring or any other means) in order to maintain models of the collaborative situation.

- Detection: Define and implement the exploitation mechanisms of the situation models in order to diagnose any source of divergence of the collaboration with regard to the expected situation.

- Adaptation: Define and implement the reaction mechanisms to deduce from the analysis of the situation models, the appropriate adjustments to propose to the running collaborative situation.

- Assessment: Define, deploy, measure and exploit Key Performance Indicators (KPI) to ensure the relevant evaluation of the consequences of the adaptation actions

This part of the research work will improve the C2NET platform by providing it with five components dedicated to meet the four objectives previously described. These five components will be: (i) a knowledge base dedicated to store the collected data as exploitable models, (ii) a first service in charge of interpreting the collected data or reference KPI to feed the knowledge base, (iii) a second service in charge of watching the knowledge base in order to detect any divergence requiring adaptation measures, (iv) a third service in charge of exploiting the knowledge base and the detection reports to deduce and define the relevant adaptation actions, and (v) a fourth service in charge of continuous assessment of the agility actions in order to evaluate the taken measures and to provide a second order of agility by allowing thus the potential improvement of the three other services. Consequently, our research framework is structured according to these five elements (a knowledge base and four services). The Figure 2 describes this research framework. 


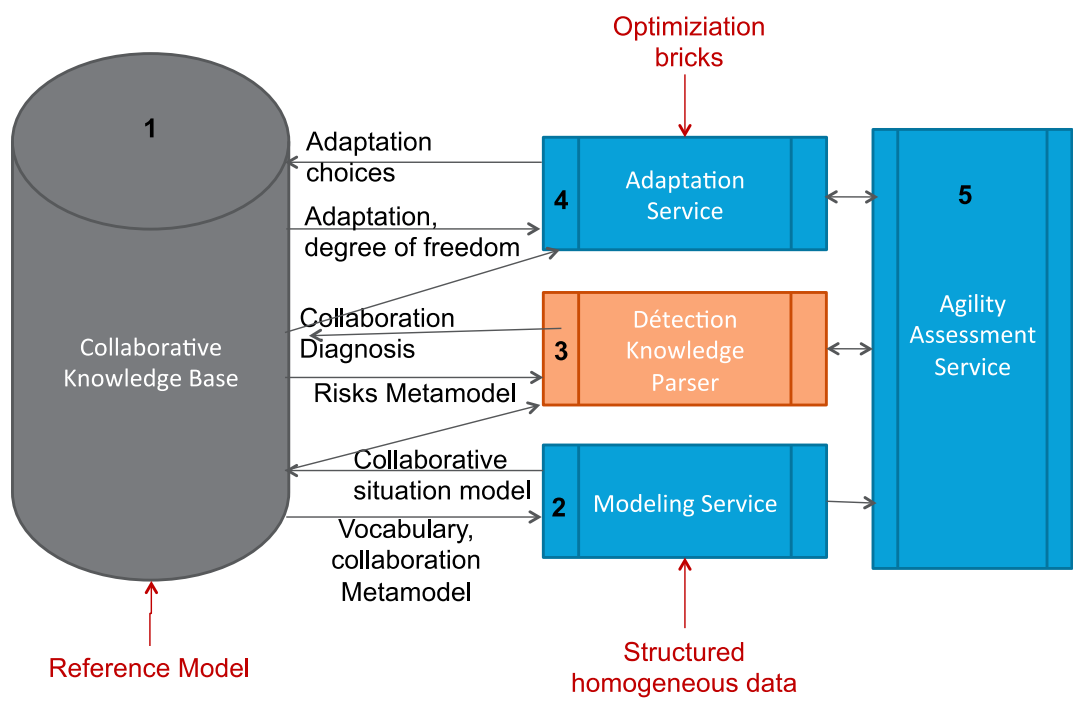

Fig. 2. Research framework proposal.

Hereafter, we give some requirements regarding tasks that have to be done to develop the previously discussed elements.

\subsection{The Knowledge Base}

Based on both a state-of-the-art on collaborative knowledge bases (domain ontologies vs. collaborative situation ontologies) and the reference models, this first design aims at defining and implementing an exploitable knowledge base about collaborative situations. This knowledge base should be compliant with any collaborative situation concerned by the C2NET project in terms of concerned business domain and concerned collaborative structure. The obtain knowledge base should be open and usable by the four agility services.

\subsection{The Modeling Service}

This second design aims at defining and implementing the first agility service. This task should define the translation mechanisms that could allow to update the knowledge base according to the continuously gathered data. This task includes a strong work on data format interpretation (syntactic view) and also on data content interpretation (semantic view).

\subsection{The Detection Service}

This third design aims at defining and implementing the second agility service. This service is responsible for the detection of irregular situations based on the captured data. Actually, once the knowledge base implemented is populated with relevant data gathered thanks to the data acquisition framework, the detection mechanism can be triggered. Furthermore, the detection mechanism can take benefit from semantically described assets and processes in order to reveal something is going wrong with the occurring process. 
Considering an enacted business process, the ability of surveying the different participants collaborating to achieve it becomes complex as these are probably belonging to different entities and abide by different rules. The adoption of the ESB technology as an interoperable framework for data collection augments the ability of applying a monitoring and detection mechanisms that will ensure such a functionality. More precisely, we will implement an event-based architecture that will subscribe to the exchanges data and that will trigger events expressing the nature of the exchange (time, sender, receiver, etc.). Once compared with the required pattern we will be able to detect if the data is relevant with regard to the required one. When the detection mechanism is not triggered by a produced event, it parses the gathered data recent and historical that is stored in the knowledge base looking for possible mismatching to start corrective procedures. Event expressing errors and specific issues are forwarded to the adaptation and assessment services.

\subsection{The Adaptation Service}

This fourth design aims at defining and implementing the third agility service. This service should use the analysis of the detection service, as well as the full knowledge base to deduce and suggest adaptation measures that could fit with the current situation and prevent its actual divergence.

\subsection{The Assessment Service}

This fifth design aims at defining and implementing the fourth agility service. This service is in charge of agility assessment (to bring agility to the agility tools). This task should define relevant KPI and also the way to improve or change the rules and mechanisms of detection and adaptation services.

\section{Expected Impacts}

By implementing the research framework previously described, this research work should be able to propose a concrete solution to support the collaborative value chain by facilitating the diagnosis of any source of divergence of the collaboration with regard to expected situation. Moreover the project will be able to support the adaptation of the stakeholders' behaviors by implementing reaction mechanisms based on global and local optimization algorithms. The research work will facilitate the coordination between stakeholders by connecting them efficiently. Particularly, this will eliminate superfluous, inaccurate or irrelevant information regarding the monitoring of the current situation. It will also automate some analysis or actions based on pre-defined business rules in order to support local or global decisions.

The results of the C2NET project will mainly apply to both large enterprises and SMEs in Industry and Non-financial services. Practically, such a contribution should allow increasing drastically the competitiveness of Supply Chains by improving: Consumers' On Time Delivery, Total Lead-Time, Time-to-Market, Inventories, Carbon footprint, Profitability ratio, Efficiency ratio... 


\section{Acknowledgement}

The research leading to these results has received funding from European Community's H2020 Programme (H2020/2014-2020) under grant agreement n636909, "Cloud Collaborative Manufacturing Networks (C2NET)".

\section{References}

1. Accorsi, R. (2011, July). Business process as a service: Chances for remote auditing. In Computer Software and Applications Conference Workshops (COMPSACW), 2011 IEEE 35th Annual (pp. 398-403). IEEE.

2. Adams, M., A.H.M. ter Hofstede, D. Edmond and W.M.P. van der Aalst. (2005, June) In Proceedings of the 17th Conference on Advanced Information Systems Engineering Forum (CAiSE05 Forum), June, Porto, Portugal

3. Ahn, H. J., Childerhouse, P., Vossen, G., \& Lee, H. (2012). Rethinking XML-enabled agile supply chains. International Journal of Information Management,32(1), 17-23.

4. Ameri, F., \& Patil, L. (2012). Digital manufacturing market: a semantic web-based framework for agile supply chain deployment. Journal of Intelligent Manufacturing, 23(5), 1817-1832.

5. Benaben, F. (2012) Conception de systèmes d'information de médiation pour la prise en charge de l'interopérabilité dans les collaborations d'organisations, Habilitation à Diriger des Recherches, INP Toulouse.

6. Camarinha-Matos, L. M., \& Afsarmanesh, H. (2005). Collaborative networks: a new scientific discipline. Journal of intelligent manufacturing, 16(4-5), 439-452.

7. Charles, A., Lauras, M., \& Van Wassenhove, L. (2010). A model to define and assess the agility of supply chains: building on humanitarian experience.International Journal of Physical Distribution \& Logistics Management, 40(8/9), 722-741

8. Christopher, M., Peck, H. (2004) "Building the Resilient Supply Chain", The International Journal of Logistics Management, Vol. 15 Iss: 2, pp.1 - 14.

9. Lee, H. L. (2004). The triple-A supply chain. Harvard business review, 82(10), 102113.

10. Poler, R., Carneiro, L. M., Jasinski, T., Zolghadri, M., \& Pedrazzoli, P. (2013). Intelligent Non-hierarchical Manufacturing Networks. John Wiley \& Sons.

11. Zhang, W., Xu, Y., \& Dong, X. F. (2012). Design and Implementation of the Agile Supply Chain Information Sharing Platform in Steel Industry based on ServiceOriented Architecture and Web Service. Advanced Materials Research,505, 75-81. 